La emergencia del paradigma emocional: una clave de la transformación de las sociedades modernas

\author{
The Emergence of the Emotional Paradigm: \\ a Key to the Transformation of Modern Societies
}

\title{
Lourdes FLAMARIQUE
}

Universidad de Navarra

Iflamarique@unav.es

Abstract: This paper examines some factors underlying the current predominance of emotional culture and outlines the resulting social scenario. Some contradictions and challenges are noted that result from the centrality of the emotional paradigm.

Keywords: Emotional culture; emotions; social change; modernity.
Resumen: En este trabajo se examinan algunos factores que han jugado a favor de la actual predominancia de la cultura emocional. Se describe a grandes rasgos el escenario social que dibuja y, en último lugar, se apuntan algunos desajustes y retos que resultan de la vigencia del paradigma emocional.

Palabras clave: cultura emocional; emociones; cambio social; modernidad.

Comprender la modernidad social y su dinámica de cambio es una de las temáticas que aglutina el pensamiento contemporáneo en todas sus variantes disciplinares. Su precedente directo son los movimientos revisionistas que, desde el siglo XIX, intentaban romper o acelerar el proceso de racionalización social en que inexorablemente parece consistir el proyecto de una cultura ilustrada. Para unos, se trataba de anticipar la sociedad verdaderamente moderna y acelerar su ritmo de transformación; para otros, urgía rescatar una racionalidad no científica que se aplique a las cuestiones morales y políticas y señale los fines que no pueden ser instrumentalizados, es decir, supeditados a los intereses de la ciencia, de la economía o, simplemente, a la eficacia.

Una constante de todas estas revisiones teóricas es que operan sobre una cuasi sinonimia entre dos categorías ya apuntadas: cambio y modernidad. Incorporadas con todo derecho al «diccionario» cultural de las sociedades occidentales apenas advertimos su insustituible contribución a la configuración de nuestra 
experiencia social, ni su «juventud» dentro de la historia de la cultura. Se podría afirmar que el cambio es la ley interna de la vida social moderna, sin que con esto se pretenda que el cambio socio-cultural sea un fenómeno nuevo; sí lo es su condición de criterio de modernidad. Por eso, la importancia del análisis de la modernidad y de su dinámica de cambio procede no tanto de su interés sociológico o de lo acertado de sus descripciones, como del hecho de que constituye la puesta de largo, la presentación pública de los implícitos filosóficos que la Ilustración y, con ella, la misma filosofía moderna ocultaban tras el ideal de un conocimiento y acción racionales.

En las últimas décadas han abundado lo que podríamos designar universales descriptivos: sociedad del conocimiento, sociedad de riesgo, sociedad postindustrial, nueva sensibilidad, valores emergentes, globalización, etc. Sea cual sea, los universales descriptivos responden a las expectativas de regularidad y homogeneidad que caracterizan toda sociedad moderna. Lo mismo sucede cuando se habla de cultura emocional, en algunos autores se trata más bien de emotivismo: una categorización hiperbólica de una dimensión que acompaña el vivir humano; con ella se pretende diagnosticar los estilos y patrones que dominan la vida social y cultural de los países occidentales. El acento de la designación 'emotivismo' revela que la valoración contiene una sospecha: la de una hipertrofia emocional y la consiguiente y excesiva responsabilidad de las emociones en la definición del tejido social y las dinámicas institucionales. En todo caso con el descriptor cultura emocional se constata el cambio de régimen emocional de las sociedades modernas y la aparición de un nuevo paradigma sociológico que ha justificado el surgimiento y desarrollo de un ámbito disciplinar propio desde los años setenta del pasado siglo: la sociología de las emociones. Desde entonces ha ido en aumento el interés por el estudio de las emociones -en qué consisten, cómo se ordenan, qué papel desempeñan en la vida social, cómo influyen en las conductas, en los usos del lenguaje, en las estrategias publicitarias, etc.- y ha contagiado a áreas como la economía, la medicina, la teoría del discurso y la comunicación y, sobre todo, la política ${ }^{1}$. Si los primeros análisis de los nuevos códigos emocio-

1 En la bibliografía básica un texto ya clásico es el de Stepjan Mestrovic, Postemotional society, London, 1997. También son reseñables: Simon J. WILLIAMS, Emotion and Theory Social: corporeal reflections on the (Ir) rational, London, 2001; Robert C. ROBERTS, Emotions: an essay in aid of moral psychology, Cambridge-New York, 2003. Igualmente los trabajos impulsados por el proyecto «Cultura emocional e identidad» del Instituto Cultura y Sociedad (ICS) de la Universidad de Navarra: Ana Marta GonZÁLEZ (ed.), The Emotions and Cultural Analysis, London, 2012 y Lourdes Flamarique y Madalena D'OliveIRA (eds.), Emociones y estilos de vida. Radiografía de nuestro tiempo, Madrid, 2013. 
nales tímidamente ofrecían una visión de las sociedades desarrolladas que contrastaba con el estereotipo de la hegemónica racionalidad científico-técnica y el procedimentalismo de las estructuras políticas, administrativas y económicas, en la actualidad nadie pone en duda que el estudio de las emociones asegura una perspectiva muy adecuada para comprender el presente e inmediato futuro de nuestro mundo moderno.

En este trabajo voy a detenerme en examinar algunos factores que han jugado a favor de la predominancia de la cultura emocional; describiré a grandes rasgos el escenario social que se dibuja y, en último lugar, apuntaré algunos desajustes y retos que resultan de la vigencia del paradigma emocional.

\section{El CAMino HaCia la CUltura EMOCiOnaL}

Una de las preguntas que se hace cualquier observador ante los cambios sociales del último siglo es cómo y por qué se ha llegado a la aludida centralidad de las emociones en sociedades que, desde hace varios siglos, profesan un culto a la racionalidad científica. Una etapa decisiva es sin duda la marcada por la primera explosión de la crisis de la modernidad ante las expectativas defraudadas por las concreciones históricas de la cultura racional, que desemboca en la pérdida de credibilidad de la razón como rectora principal del gobierno tanto del bien común como de la propia vida. Pasado el tiempo, podemos ver como una prefigura de lo que iba a suceder en todos los órdenes la revolución en el arte de vanguardia, que ya estaba en marcha con el abandono de la perspectiva central, la ruptura de planos y la introducción del tiempo en la pintura. Siguiendo el paso de esa revolución, la novela trata principalmente sobre el mundo interior y la psicología de los personajes (sus sueños y anhelos más íntimos) y, en menor medida, sobre las acciones; se favorece la mezcla de géneros en todas las expresiones artísticas y se ensayan lenguajes más conformes al carácter vivencial de lo narrado. Como en el arte, las transformaciones que se dan en la mentalidad y formas de vida suponen el rechazo de lo racional y universal, ordenado y previsible, de lo meramente objetivo y conforme a leyes. También como sucede en el arte o en la literatura, se configura un nuevo horizonte de la acción social sin cánones, en el que el individuo sólo se tiene a sí mismo para crear la norma.

Pero, si a alguno de nuestros contemporáneos puede haberles pillado por sorpresa el auge del paradigma emocional, los clásicos de la sociología del siglo XX identificaron su germen como uno de los rasgos definitorios de la modernidad. Con una autoridad indiscutida, Georg Simmel vio con claridad que la 
modernidad significa un modo particular de experimentar el mundo, que no se reduce a nuestras reacciones interiores ante los sucesos, sino que proporciona el contenido principal de la vida íntima. Su diagnóstico es certero y profético:

la esencia de la modernidad como tal es psicologismo, la experiencia e interpretación del mundo desde el punto de vista de las reacciones de nuestra vida interior y, además, como un mundo interior, (es también) la disolución de los contenidos fijos en elementos fluyentes del alma, de la que se ha separado toda sustancia y cuyas formas son simples formas del movimiento ${ }^{2}$.

Porque para el habitante de la urbe moderna, el mundo exterior es ante todo mundo interior y de este modo un vertiginoso cambio de sensaciones y experiencias. Las palabras de Simmel anuncian un fenómeno cuya magnitud y significado no han sido evidentes hasta la segunda mitad del siglo XX, cuando la gran mayoría de los ciudadanos de las sociedades modernizadas viven en ciudades. La carencia del suelo firme que proporcionan la tradición, la autoridad y las costumbres heredadas, por un lado, y la transitoriedad y caducidad de las formas de vida que se reducen a simples modas, por otro, han debilitado el peso de las instituciones socio-políticas en la conformación de las sociedades urbanas; éstas se configuran fundamentalmente a partir de las relaciones que establecen los individuos en respuesta a las múltiples y variables impresiones recibidas.

Simmel detectó que, en medio del clamoroso esplendor de la era científicotecnológica, la seguridad interior del individuo es reemplazada por una vaga nostalgia, una urgencia desasistida que se origina en la hiperactividad y la excitación de la vida moderna (el tumulto de la metrópolis, la manía de viajar, la competición salvaje, la deslealtad en las opiniones, en el gusto, en el estilo). Advierte que la vida de la ciudad favorece el surgimiento de las enfermedades psíquicas, de la neurosis. Para no tener la sensación de estar oprimido por las exterioridades de la vida moderna y al no poder soportar los cambios permanentes, el hombre de nuestro tiempo tiende a crear una distancia entre él y el entorno social y físico. El habitante de la ciudad, sigue Simmel, se defiende del trepidante flujo de impresiones, de la constante variación de puntos de vista a la que le somete la gran ciudad y le produce un desarraigo del medio ambiente externo, con el entendimiento, es decir, con una mayor racionalización y objetivación.

Esta defensa frente a la sobreexcitación nerviosa es, en realidad, indiferencia hacia lo individual, lo particular en lo que, por otro lado, se sustentan las relacio-

2 Georg Simmel, Philosophische Kultur, Gesamtausgabe Bd. 14, Frankfurt, 1996, p. 346. 
nes interpersonales. La distancia psicológica de la que habla Simmel puede manifestarse como hipersensibilidad y alguna forma de fobia. Pero también como una indiferencia total o hastío. En definitiva, la vida urbana favorece la indolencia, el embotamiento ante las diferencias de las cosas, no porque no sean percibidas, sino porque su significado y su valor son irrelevantes: «este estado de ánimo es el fiel reflejo subjetivo de la economía monetaria» ${ }^{3}$.

Valéry describe la psique moderna con caracteres muy semejantes: avidez activa, curiosidad ardiente y desinteresada, una mezcla feliz de imaginación y rigor lógico, un cierto escepticismo no pesimista, un misticismo no resignado ${ }^{4}$. Esa psique corresponde a lo que Valéry llama el estado de crisis: no hay principios, ni verdad que no estén sujetos a revisión; tampoco hay acción que no sea convencional, ni ley que no sea aproximativa. El hombre del que hablan las ciencias o las instituciones modernas está muy lejos del hombre real, marcado por un desorden íntimo, por la existencia de contradicciones entre nuestras ideas y las inconsecuencias de nuestros actos. «El hombre moderno -y en esto es modernovive familiarmente con una cantidad de contrarios establecidos en la penumbra de su pensamiento y que aparecen en escena alternativamente ${ }^{5}$. Todo esto lleva al naufragio del espíritu.

Valéry señala otros aspectos significativos de la situación del hombre en las sociedades modernas: sumergido en el universo humano, se encuentra rodeado de otros seres humanos, siendo cada uno como el centro de un pueblo de semejantes, el único y, sin embargo, tan sólo es una unidad dentro de ese número indeterminado; es incomparable y, a la vez, cualquiera. Sus relaciones con los demás son una de sus ocupaciones más importantes, y están caracterizadas por la tensión de querer ser él y tener que reconocer un mundo social de voluntades como la suya ${ }^{6}$.

El reconocimiento del diagnóstico sobre la modernidad que hacen Simmel y Valéry ha llegado pasados los años sesenta, cuando los cambios sociales dejaron a la vista la profunda revolución del yo operada por la modernidad. No es casual que una de las teorías de moda en esos años fuera el psicoanálisis. Porque si la vida urbana es un condicionante principal de las transformaciones sociales que justifican hablar de cultura emocional e incluso de un cambio de régimen de las emociones, otro elemento clave es la concepción del psiquismo de Freud. La

\footnotetext{
3 ID., Die Grossstädte und das Geistesleben, Gesamtausgabe Bd. 7, Frankfurt, 1995, p. 121.

4 Cfr. Paul ValérY, La crise de l'esprit, Oeuvres I, Paris, 1968, p. 996.

5 Ibid., pp. 1018, 1030.

6 Cfr. Paul VAlÉRY, La politique de l'esprit, Oeuvres I, p. 1029.
} 
normalidad con la que son interpretados los «sentimientos encontrados» ha favorecido que las problemáticas sentimentales, la emotividad en general, sean temas habituales de conversación y hayan generado un lenguaje propio que, compartido primero entre los habitantes de las ciudades, hoy día ya es común al mundo civilizado.

Como ha expuesto brillantemente E. Illouz, a quien sigo en este punto, el psicoanálisis tenía por objeto la reconfiguración de la vida emocional; para ello proponía terapias que inspiraron el estilo emocional terapéutico dominante en el panorama cultural estadounidense del siglo XX (y desde la segunda mitad del siglo en el europeo). Este estilo emocional terapéutico resultaba de la preocupación por la vida emocional, su etiología, y por el desarrollo de técnicas específicas -lingüísticas, científicas, interactivas- para comprender y manejar esas emociones. Así, el psicoanálisis, mejor dicho, sus ideas sobre el yo, la vida emocional y las relaciones sociales entraron a formar parte del imaginario común tanto para la cultura popular como para la de élite 7 . Por su «ecosistema», el psicoanálisis es un paradigma urbano.

Uno de los ámbitos en los que tiene claras consecuencias la emergente concepción del yo es en la concepción de la familia. En mi opinión, de todas las revoluciones así identificadas a lo largo del pasado siglo la que tiene un alcance más universal es la transformación de la vida privada, de la esfera más personal: una revolución acelerada en gran medida por la asimilación del pensamiento y lenguaje freudianos. Silenciosamente u ostentosamente, en ambientes artísticos y en la cultura popular, se sustituyó la definición burguesa o heroica de la identidad (sustitución iniciada por el arte ya en el siglo XIX) por una identidad forjada en el lugar de trabajo, en la familia ${ }^{8}$. Si antes la familia cumplía principalmente la función de situar en el mundo a través del estatus social heredado, si era la transmisora de creencias y prácticas sociales que garantizaban la socialización eficaz de sus miembros, en la nueva cultura emocional (impregnada del psicologismo psicoanalítico) es el inicio de la vida de cada individuo, el hecho biográfico que se arrastra simbólicamente toda la vida. Se podría decir que la pérdida de relevancia social de la familia se equilibra con el fenómeno contrario: una mayor responsabilidad en la conformación del yo personal. «La familia desempeñó un papel crucial en la constitución de las nuevas narrativas de la individualidad, dado que era tanto el origen mismo del yo como aquello de lo que el

7 Cfr. Eva Illouz, Intimidades congeladas. Las emociones en el capitalismo, Buenos Aires, 2007, pp. 22-23.

8 Cfr. ibid., p. 26. 
yo tenía que liberarse»` ${ }^{9}$ Además, Freud colocó la sexualidad en el epicentro de esa nueva arquitectura emocional (como causa de enfermedades o como signo de madurez); pero, como apunta acertadamente Illouz, lo que permitió que la sexualidad se incorporara con tanta facilidad al imaginario moderno fue su traducción e incorporación al lenguaje común, situándose lejos de la connotación «primitivista» de la sexualidad del siglo XIX ${ }^{10}$.

Esto fue solo el comienzo. A lo largo del siglo XX el mundo de las emociones y sentimientos se traslada al ámbito de la educación, de la actividad económica, de la cultura popular, etc. En los años sesenta coinciden movimientos sociales (movimiento hippie, revolución sexual, mayo del 68...) que priorizan la dimensión emocional sobre la racional. Se inicia el asalto y demolición de las instituciones que habían gobernado hasta entonces las esferas pública y privada. Se hacen algo habitual prácticas como motivar, incentivar el aprendizaje, la productividad o la participación social, etc. Los psicólogos desarrollan ideas y métodos para optimizar las relaciones humanas. Se proponen nuevos modelos de comportamiento basados en la comunicación del mundo interior, de las emociones y sentimientos, que garantizan un mejor funcionamiento de las organizaciones humanas, sean estas empresariales, educativas o familiares.

Son algunos ejemplos de lo que en trabajos anteriores he descrito como la imparable psicologización de la experiencia social ${ }^{11}$ que ofrece las condiciones para el actual predominio del paradigma emocional. De ello han tomado buena nota los enfoques del pensamiento sociológico de las últimas décadas que tratan de objetivar los síntomas principales de las transformaciones sociales: sociedad líquida, cansancio, transparencia, ligereza ${ }^{12}$, riesgo (Bauman, Beck); y se habla de biopolítica, psicopolítica (Foucault, Agamben, B.-C. Han). En ellos el interés investigador se desplaza de las instituciones y procesos sociales y políticos hacia las

9 Cfr. ibid., p. 25.

10 Cfr. ibid., pp. 27-28.

11 Lourdes FlamariQue, Emociones versus normas. La psicologización de la experiencia social, en Pensamiento y cultura, 12/2 (2009), pp. 321-339.

12 En un trabajo reciente, Lipovetsky argumenta que vivimos la era del triunfo de la ligereza tanto en el sentido propio del término como en el figurado. La ligereza servida por los medios gobierna la cultura cotidiana con una continua referencia hedonista y lúdica al universo del consumo. hedonistas y lúdicas «La ligereza era un ideal estilístico o un vicio moral. Se ha convertido en una dinámica global, un paradigma transversal, un hecho-social-total cargado de valor tecnológico y económico, funcional y psicológico, estético y existencial. Ahora, abundan los campos que expresan el combate de lo ligero contra lo pesado. La era hipermoderna es inseparable de una revolución multidimensional de la ligereza cuyo rito es vertiginoso». Gilles LIPOVETSKY, De la légèreté, Paris, 2015 (traducción propia), p. 13. 
impresiones, vivencias y emociones que sostienen básicamente la realidad social y ponen de manifiesto la dimensión reflexiva de toda acción. La frecuencia con la que se generaliza el uso de un descriptor sociológico es indicativa no solo de la pulsión moderna por las predicciones sociales, sino también del carácter performativo que tienen esas predicciones y diagnósticos sobre la realidad examinada.

Si para detectar la creciente presencia de elementos emocionales en el discurso y la vida pública occidentales no fuera suficiente analizar los estilos de vida, las formas de socialización, o la evolución de realidades institucionales como la política, la enseñanza, bastaría examinar las formas de ocio, el consumo y la publicidad y, sobre todo, los productos de la cultura popular, como el cine, la música o la televisión para encontrar un amplio y variado muestrario de las expresiones del emotivismo, y reconocer los nuevos códigos emocionales que no solo han calado hasta el fondo del psiquismo y las mentalidades contemporáneas, sino que además han seguido el patrón globalizador, sin apenas encontrar barreras en otras tradiciones culturales y religiosas.

Los periódicos de cualquier país occidental, los programas televisivos de noticias o de participación social son excelentes escaparates de un lenguaje y acciones que responden en gran medida a significados emocionales, apelan a sentimientos, o identifican el sentido y valor de lo narrado de acuerdo con las emociones a favor o en contra que suscitan. Sus protagonistas encarnan un tipo de juicios: juicios emocionales que no informan ni se pronuncian sobre la rectitud o no, ni sobre el bien o el perjuicio social de los actos y situaciones que se aprueban o rechazan. Se trata de legitimaciones o condenas de conductas y personas apoyadas fundamentalmente en los sentimientos que despiertan en los observadores, o en la carga sentimental con la que los actores sociales exponen y defienden los actos. Para unos y otros lo decisivo es la respuesta emocional, la vivencia personal. Todo debe ser personalizado (psicologizado), por ejemplo, las noticias contadas por alguien que estaba allí; importa más lo que sintió que lo que sucedió, los motivos por los que hizo esto o aquello que lo que hizo y las consecuencias que se siguen. Hay que mostrar las emociones, expresar los afectos más íntimos, cuanto más emotivo y vulnerable se muestre uno, más verdadero.

\section{LA SIGNIFICATIVIDAD DE LAS EMOCIONES Y LOS NUEVOS CÓDIGOS SOCIALES}

Como primera aproximación se puede decir que las emociones y afectos son la respuesta espontánea de la subjetividad ante la realidad concreta experimentada que despierta en el individuo agrado o rechazo: comportan por tanto una 
valoración que se articula como un estado emocional o afectivo. Pero, lejos de tener su espacio exclusivamente en la intimidad de cada persona, en nuestra época son parte insustituible de la vida y estructura social: no recluyen al individuo en un ámbito privado, sino que tienen una notoria presencia pública, también en la esfera económica y política. Las emociones comportan significados culturales y sostienen, generan o destruyen relaciones sociales. En la medida en que las emociones revelan aspectos irreflexivos y profundamente interiorizados de la acción, a menudo son también síntomas de «enfermedades sociales» como el estrés o la depresión, pues las expectativas felicitarias, universalizadas con el proyecto moderno, están sostenidas y alimentadas por una compleja red de emociones. Como he apuntado ya, el estudio del régimen emocional se ha abierto paso como una de las perspectivas más fecundas para la comprensión de los cambios sociales de las últimas décadas.

Invertimos buena parte de nuestra energía en la vida emocional tanto en el ámbito familiar, de amistad, como en el laboral. Por todo ello se entiende que una de las ideas que más fortuna ha tenido en la aplicación del paradigma emocional a las distintas esferas de la existencia es «la gestión de las emociones». Se organizan cursos sobre las ventajas de todo tipo que ofrece su control; se promueve la educación emocional a todos los niveles, y desde las escuelas hasta en la formación de directivos se prescriben técnicas y estrategias que combinen el dominio y la comunicación eficaz de emociones. Todo ello presupone que detrás de la gestión de las emociones hay un yo capaz de sentir, un yo que tiene una posición activa con relación a sus emociones. La socióloga A. R. Hochschild, una de las pioneras en el estudio de la gestión emocional, ha mostrado que con la gestión emocional no se trata sólo de manejar la exteriorización de las emociones con vistas a lograr determinados objetivos, sino, en primer lugar, de sentir lo que se considera adecuado. Esto requiere un código, con sus normas y signos, y aprender a usarlo: se trata de ordenar (management) el propio sentimiento, es decir, de producir cambios en los sentimientos que faciliten «sentir lo que se quiere sentir» (por ejemplo, utilizar las herramientas y técnicas emocionales, psicológicas, necesarias para convertir un sentimiento de desánimo en un sentimiento de ánimo y energía) ${ }^{13}$. Hochschild identifica tres técnicas básicas para esta elaboración de las emociones: una de tipo cognitivo que consiste en cambiar imágenes, ideas o pensamientos y con ello los sentimientos asociados. Otra de tipo corporal: lo que se cambia

13 Cfr. Arlie Russell Hochschild, La Mercantilización de la vida íntima. Apuntes de la casa y del trabajo, Madrid, 2008, p. 136. 
son los síntomas somáticos u otros síntomas físicos de la emoción (por ejemplo, respirar lentamente o eliminar el temblor). En tercer lugar, hay una elaboración expresiva de las emociones: trata de cambiar gestos expresivos con el propósito de cambiar sentimientos (por ejemplo, tratar de sonreír o de llorar) ${ }^{14}$.

De todo ello se sigue, en primer lugar, que las emociones y los sentimientos no son solo respuestas espontáneas e imprevisibles, sino que responden también al trabajo, al esfuerzo consciente de un yo sintiente, capaz de ocasionar cambios en el valor e intensidad de una emoción o en sus propiedades. Como han advertido ya los gestores económicos y los expertos en comunicación política o en educación, desde el punto de vista personal y social cabe esperar mucho de la correcta elaboración de las emociones ${ }^{15}$. En segundo lugar, queda claro que las emociones no emergen como episodios aislados, casi irracionales. Todo lo contrario, se revelan como insertas en una red de significados y estableciendo relaciones con sentido y valor intersubjetivos. Así pues, el lenguaje emocional, su semántica y sintáctica son un campo privilegiado de análisis con vistas a entender y, por qué no, predecir los fenómenos de cambio y las tendencias emergentes que terminan por configurar formas de vida bastante homogéneas en cualquier parte del mundo conectado con el resto por los medios de comunicación. A la ambigüedad significativa de toda emoción se añade la modificación que resulta de su lugar en el contexto, en el conjunto expresivo que proporciona su sentido concreto a cada elemento, a cada componente emocional.

Además de su carácter codificado y eminentemente social, cabe preguntarse si hay algún otro rasgo específico del paradigma emocional contemporáneo que lo distinga de épocas anteriores. En cierto modo, esto ha sido sugerido ya por las reflexiones precedentes al hablar de un cambio del régimen emocional en las sociedades hipermodernas de este siglo: su factor diferencial es precisamente la condición «moderna» del nuevo paradigma. A esto apunta A. M. González cuando destaca que «el actual énfasis en las emociones no ha supuesto un retroceso de la racionalidad estratégica, tal vez porque, en realidad, la misma racionalidad estratégica esconde un cierto tipo de hombre emocional» ${ }^{16}$.

14 Ibid., pp. 142-143. Sobres estas cuestiones trata con detalle el excelente estudio de M. D'OLIVEIRAMARTINS, Arlie Russell Hochschild. Un camino hacia el corazón de la sociología, Madrid, 2018, pp. 93-107.

15 «La elaboración de las emociones difiere del 'control' o de la 'supresión' de las emociones. Estos dos últimos términos sugieren un mero esfuerzo por aplastar o evitar los sentimientos, mientras que el concepto de 'elaboración' se refiere de manera más amplia, al acto de evocar o configurar el sentimiento, así como al de suprimirlo». Arlie Russell HocHSCHILD, La Mercantilización..., op. cit., p. 141.

16 Ana Marta GONZÁLEZ, Introducción: emociones y análisis social, en Lourdes FLAMARIQUE y Madalena D'Oliveira (eds.), Emociones y estilos..., op. cit., p. 12. 
Los actuales estudios de cultura emocional van en esta línea. Desde que Proust afirmara que las emociones son «levantamientos geológicos del pensamiento», se ha reconocido ampliamente su valor cognitivo, más allá de su catalogación como meros impulsos afectivos, desligados de nuestros juicios y valoraciones. La significatividad de las emociones exige pensarlas en relación con el conocimiento, es decir, no como meramente subjetivas, opuestas a lo objetivo. No se trata únicamente de conocer los códigos y lenguajes que rigen el despliegue emocional en sociedad, sino de aquilatar la estructura cognitiva de las emociones de manera que puedan ser incorporadas con voz propia a la configuración de las ideas y principios que orientan la vida personal y social. En esa línea se ha pronunciado Martha Nussbaum, al proponer la inclusión de las emociones como parte del pensamiento ético, del razonamiento moral que hace todo agente. Según Nussbaum, si consideramos las emociones como una respuesta inteligente a la percepción del valor, es decir, si las emociones están imbuidas de inteligencia y discernimiento, no pueden dejarse al margen del juicio ético. La moralidad no puede consistir tan solo en un sistema de principios intelectuales al lado de las emociones que apoyan o dificultan nuestras elecciones ${ }^{17}$. Pero, si las emociones son cierto tipo de juicios, pueden acertar o errar, ser verdaderos o falsos. No se puede ignorar que tienen un papel en el pensamiento acerca de lo justo y lo bueno. Pero, ¿¿cuál es su relevancia?, ¿cómo se conjugan con el conocimiento y la experiencia moral? ¿En qué medida deben ser fomentadas en la actividad política?

Para responder a estas preguntas y hacerse cargo mejor de los elementos que definen el paradigma emocional es preciso tener en cuenta que los nuevos códigos emocionales y la resignificación social de determinadas emociones se deben en buena medida a la eficaz colaboración que han prestado en el desarrollo de las revoluciones en los estilos de vida, en las demandas sociales, o en el consumo. Como he apuntado ya, hablamos de cultura o paradigma emocional porque, además de los aspectos ya señalados, en las últimas décadas se ha generalizado un nuevo modo de socialización (empatía emocional), lo que ha traído el desarrollo de un código social capaz de sustituir las reglas del juego político y moral que han caracterizado la vida urbana de las sociedades modernas. Como las demandas

17 Martha Nussbaum, Paisajes del pensamiento. La inteligencia de las emociones, Barcelona, 2008, pp. 21-22. «Concebir las emociones como elementos esenciales de la inteligencia humana, y no como meros apoyos o puntales de la inteligencia, nos proporciona unas razones especialmente poderosas para fomentar las condiciones del bienestar emocional en una cultura política, pues esa concepción implica que, sin desarrollo emocional, una parte de nuestra capacidad de razonar como criaturas políticas desaparecerá» (ibid., p. 23). 
individuales sólo son verdaderamente tales si recogen necesidades que el individuo percibe de manera singular e intransferible, estas terminan por formularse en base a emociones; el recurso a conceptos, la apelación a la naturaleza o a la tradición son vistos como una agresión, la de una racionalidad «inhumana» contra la verdad de los sentimientos. Así, cada vez en mayor medida los «contenidos políticos» que conforman la opinión pública se reducen a lo existencial, a lo que emociona y despierta simpatía en la gente. El ocaso de los ideales sociales y los valores políticos en los países occidentales ha dejado el espacio libre a la búsqueda del propio interés, de la felicidad personal y al consumo como una forma de entretenimiento. Los proyectos que impulsan los partidos políticos han dejado atrás en buena medida las ambiciones sociales y colectivas para defender los deseos individuales, traduciéndolos en derechos. Ahora se trata de pulsar el estado emocional, descubrir aquello con qué sintonizan los electores y asumir posibles sueños o ilusiones en los programas electorales.

También aquí se manifiesta esa alianza de emotivismo y racionalidad tan característica de las sociedades tardomodernas. El objetivo principal queda resumido en un ideal político que se generaliza en las últimas décadas del pasado siglo: Estado del bienestar. Se trata de un bien del que disfruta el ciudadano gracias al funcionamiento del orden institucional y al sistema de producción capitalista; los ciudadanos quedan bajo la total tutela del Estado y esto tiene consecuencias. En la práctica política se detecta tedio en la misma medida en que los procedimientos de elección, representación y distribución del bienestar operan sin sobresaltos, pero también dentro de límites inamovibles. La atención ciudadana se dirige hacia otras cosas. No se trata de que las expectativas no se hayan cumplido: en lo sustancial los ciudadanos están conformes con el régimen institucional. Es más bien que las expectativas son ahora de tipo individual, no universal. La debilidad del imaginario político colectivo, que no es capaz de hacer frente al sistema técnico-económico impenetrable a las razones políticas o morales, lleva inexorablemente a refugiarse cada vez más en la esfera privada. El resultado es en buena medida fragmentación. No hay bienes comunes, la prosecución de fines sociales es cosa del pasado, la desigualdad invita a la creatividad y competencia: ahora lo importante son las estrategias, y cada uno establece las suyas.

Esa bien sintomática la forma de individualismo que sigue a la privatización de los fines y a su paulatina transformación en simples deseos. El tiempo vital se acorta por el abandono de la esperanza en un bien futuro a favor de la satisfacción inmediata del deseo de algo en el presente. Lipovetsky acertó al entender que el individualismo contemporáneo no es el símbolo de una decadencia, sino la abolición de lo trágico de la existencia: es el repliegue hacia la esfera privada en la 
que sin ideales los seres humanos aspiran tan sólo a ser felices. Se ha producido el fin del homo politicus y el advenimiento del homo psicológico que sólo cree en su bienestar ${ }^{18}$. Este descriptor sociológico denota, sin embargo, una crítica (narcisismo), incluso una añoranza. Al homo psychologicus se le considera la última forma de individualismo, la más consumada. Se trata, además, de la «última figura del individualismo» porque ya no aspira a una independencia soberana asocial, sino que se ramifica en asociaciones y colectivos con intereses miniaturizados, hiperespecializados ${ }^{19}$. Recientemente, algunos movimientos sociales han activado un estado emocional de descontento y articulado una estructura que pueda darle visibilidad y sostenibilidad como principal argumento político.

Para este homo psychologicus los agravios colectivos se han transformado en problemas personales que pueden someterse a intervención terapéutica. En el imaginario moderno la forma plena humanidad pasaba por el ámbito de lo público, de la participación social. Los nuevos narcisistas son los hombres psicológicos capaces de analizar y evaluar el estado del mundo sólo a través del prisma de sus problemas personales, no viven obsesionados por la culpa, sino por la ansiedad. Si el curso histórico parece escapar definitivamente a nuestra intervención, nos queda sólo el curso de la propia vida. Cada uno puede concentrar sus intereses en lo íntimo y personal, en su vida y en el ejercicio de sus posibilidades: aquí es donde realmente se la juega. Se trata de una nueva interpretación de la modernidad que principalmente promueve la exaltación del bienestar y el autogobierno personal: es el repliegue hacia la esfera privada en la que sin ideales los seres humanos aspiran tan sólo a ser felices. Curiosamente esta forma banal (políticamente hablando) de vivir es la mayor fuente de ansiedades e incertidumbres. Nuestras elecciones versan sobre los asuntos privados en los que se presentan múltiples opciones, demasiadas tal vez, pues en el marco normativo moderno y postmoderno se equipara todo aquello que cumple un mínimo de racionalidad.

Como era previsible, el emotivismo contemporáneo ha sido domesticado principalmente por el mercado y la cultura mediática, y disponemos ya de una amplia tipología emocional, con su lenguaje gestual y verbal, sus expresiones personales y colectivas. Por eso, para entender cómo el nuevo paradigma emocional es un factor de socialización principal en las sociedades desarrolladas, es preciso examinar la correlación consumo-emociones. Las estrategias del consumo han

18 Cfr. Gilles Lipovetsky, La era del vacío, Madrid, 1987, p. 130.

19 Cfr. ibid., p. 13. 
accedido a las esferas más íntimas del individuo transformando sus deseos y anhelos en conductas previsibles y habituales ${ }^{20}$. Como consumidores, nos creemos independientes: en la publicidad, el deseo se presenta unido a la aspiración a la vida buena, a la felicidad y autorrealización; de este modo se impone con una fuerza que a veces oculta su carácter de mera respuesta a un estímulo. Las estrategias comerciales se dirigen siempre a los individuos como tales, de manera que en el mensaje o discurso y en el producto mismo, el consumidor cree reconocerse personalmente y lo hace suyo como si fuera su autor; cuando en realidad, expuesto a técnicas de marketing sofisticadas, parece confirmar los planteamientos conductistas, psicologistas e incluso estructuralistas que ponen en entredicho su condición de agente libre.

No sorprende que la publicidad haya incorporado y dado prioridad a la narrativa identitaria en sus anuncios frente a la información sobre las propiedades del producto (por ejemplo, los anuncios de automóviles muestran una tipología rica y sumamente elocuente respecto a las categorías sociales y morales con las que trata de reconocerse el ciudadano medio). Se considera que lo subjetivo y personal se muestra también en lo más superficial y accesorio; en consecuencia, adoptando ciertos «modos y modas» elegimos no sólo un estilo de vida, sino que realizamos nuestro ser más propio.

La misma tendencia individualizante se percibe en la evolución de las prácticas de ocio y consumo, el desarrollo del deporte o la moda, en el peso creciente de la imagen en las relaciones humanas, en la celebración del dispendio y el gasto, la mistificación de las transgresiones en la esfera de la sexualidad, la exhibición pública de la intimidad ante una audiencia anónima, la extensión del voyeurismo y la curiosidad por las vidas ajenas mostradas en los medios de comunicación.

A consecuencia de todo esto, nuestro mundo es rapsódico, caracterizado por fragmentos de experiencias que captamos mediante actitudes emocionales, $\mathrm{y}$ no mediante el razonamiento o el juicio. La misma necesidad de cambio en los útiles culturales, el consumo de las formas artísticas, se da en el ámbito de los ideales políticos y morales. Precisamente, la transitoriedad de la vida emocional, ha incrementado el traslado de las responsabilidades éticas a los entes abstractossociales.

20 Como ha señalado Hochschild, los llamados «valores familiares» cotizan al alza lo que ha favorecido la invasión del mercado en la vida familiar, en la organización doméstica: empresas de servicios que tratan de suplir el rol de esposa-madre, convirtiendo en mercancía los servicios que han caracterizado secularmente a la familia. Cfr. Arlie Russell HocHSCHILD, La mercantilización..., op. cit. 


\section{EMOTIVISMO MORAL Y NUEVA CULTURA POLÍTICA}

En esta última parte quiero referirme brevemente a los retos que presenta el escenario descrito. En él destacan dos efectos que es preciso tener en cuenta cuando enfrentamos los grandes problemas éticos y políticos de nuestro tiempo: por un lado, la subjetivización de todas las dimensiones que han dignificado la vida pública, política y moral de Occidente; y, por otro, la transformación en cuestión de interés social de tareas antes apenas valoradas, configurando así la nueva agenda moral de las sociedades ultramodernas.

El abanico de esta nueva agenda es cada vez más amplio, precisamente por las dinámicas de individualización y psicologización ya apuntadas. Por ejemplo, al reiniciarse la actividad laboral tras las vacaciones, se habla de estrés postvacacional y se inunda los medios de comunicación de consejos para adultos y niños en su vuelta al trabajo y a la escuela. Hoy día casi todo se dramatiza, produce estrés: la edad, el aumento de peso, tener hijos adolescentes, la competitividad laboral, la competitividad escolar. Sin duda, la vida actual es cada vez más exigente en todos los terrenos, pero igualmente forma parte de nuestra autocomprensión el valorar el mundo que vivimos, la realidad que se nos ofrece en categorías psicológicas, emocionales. En relación con el propio bienestar.

A esta tendencia que antepone bienes e intereses particulares, pero igualmente a la demanda de un vínculo emocional con la causa que sea como medida de confianza, responde en parte el movimiento asociacionista de los últimos años. Mientras que las grandes organizaciones políticas o sindicales que congregaban las fuerzas vivas en las sociedades modernas del siglo XX apenas reciben nuevos afiliados, se multiplican las asociaciones y grupos que reúnen a quienes comparten un mismo problema (asociaciones de afectados o victimas) y encuentran alivio en el contacto con otros que padecen lo mismo, y con los que tal vez se pretenda elevar a la categoría de derecho una situación, una diferencia, una particularidad. Con planteamientos muy semejantes, estas formas de asociacionismo ponen el acento en los aspectos más subjetivos de problemas o situaciones contrarias al ideal de bienestar que ha impulsado el cambio social ${ }^{21}$. $\mathrm{Al}$ mismo tiempo, los elevan a cuestión de interés social, ofreciendo así material para una agenda moral de alcance global. Un fenómeno característico de esta

21 Lipovetsky habla de la «última figura del individualismo» que ya no aspira a una independencia soberana asocial, sino que se ramifica en asociaciones y colectivos con intereses miniaturizados, hiperespecializados. Cf. Gilles LIPOVETSKY, La era del vacío..., op. cit., p. 13. 
nueva agenda es la instauración del «día mundial de...»: el espectro es tan amplio que acoge por igual «el día europeo para el uso prudente de antibióticos», «el día mundial del árbol» o «día mundial del niño no nacido». Se trata de una práctica aleccionadora con la que las instituciones públicas tratan de educar a la ciudadanía en una determinada dirección ética. Los argumentos de que se sirven son principalmente la empatía que despiertan quienes personifican el problema o cuestión a la que se dedica el día.

La primacía de las emociones se nota también en los modos de ejercer la sociabilidad. Muchas encuestas dan cuenta del significativo descenso de los «amigos íntimos» en los países industrializados; junto a esto, las redes sociales proponen un amplio concepto de la amistad sin fronteras (un adolescente puede presumir de tener más de cien amigos), ni mayores exigencias que el tiempo que se les dedica. Desaparecen o disminuyen los amigos/as íntimos/as, pero aumentan como hongos los «amigos». Se pide, por favor, marcar con un like cualquier intervención en las redes como signo de amistad.

Si estos diagnósticos de la vida moderna son acertados, entonces el individualismo no puede ser visto como resultado del advenimiento de la modernidad, un producto incluso de la secularización y del escepticismo moderno. Bauman considera que el orden es inverso: «debido a que los acontecimientos modernos arrojaron a hombres y mujeres a la condición de individuos -fragmentando su vida, dividida en varias metas y funciones apenas relacionadas que debían llevar a cabo en un contexto diferente y conforme a una pragmática distinta-, la idea 'abarcadora' de una visión unitaria del mundo resultó poco útil y difícilmente logró captar su imaginación $\gg^{22}$. Carentes de un sustrato pre-político, y estando bajo sospecha la racionalidad moderna, ya no parece posible promover la vigencia pública de unos principios morales permanentes: «porque los ciudadanos no estamos de acuerdo en ningún ideal determinado de vida buena, de manera que imponerles uno de ellos iría en contra de la libertad individual de pensamiento y expresión $»^{23}$. Si queda todavía algún camino para esta aspiración, no hay duda de que atraviesa los campos de las emociones y de las categorías psicológicas con las que actualmente articulamos la experiencia.

Si antes hablaba de un cambio de régimen emocional es inevitable preguntarse si la cultura emocional no ha traído consigo un cambio de paradigma ético. Esto lo vieron hace tiempo los estrategas de la publicidad y la cultura audiovi-

22 Zigmunt Bauman, Ética posmoderna..., op. cit., p. 12.

23 Alejandro LlaNO, Humanismo cívico, Barcelona, 1999, p. 150. 
sual y más recientemente los de la política. Si queda todavía algún camino para la vieja aspiración a una ética racional y universal que sea capaz de cohesionar el tejido social, no hay duda de que atraviesa el campo de las emociones y de las categorías psicológicas con las que actualmente articulamos la experiencia. Sirva como ejemplo el fenómeno mediático de la confesión exculpatoria: se cuenta todo tal como fue vivido, se exponen públicamente los sentimientos, los motivos o detalles íntimos de un episodio de la propia vida: la autenticidad o sinceridad es criterio de moralidad de lo hecho, aunque sea, por ejemplo, adulterio; el sufrimiento exhibido y si es posible recreado, exculpa de la injusticia y el mal infringido (los reality shows viven de esto).

Richard Sennett hablaba en este contexto de «comunidad destructiva»: aquélla que destruye metódicamente a sus miembros a través del culto sin freno a la sinceridad; sentimientos, que son y deberían ser íntimos, son confiados a otros. Con esa renuncia se busca en último término la aprobación de los comportamientos y los actos. Ahora bien, no está en juego que el sentido de la acción pueda ser entendido y aceptado por otros, sino que la transparencia de las emociones del que se sincera compromete a priori la aprobación ajena, es decir, fuerza que otros aprueben las acciones ${ }^{24}$. El pronóstico de Sennett (de hace cuatro décadas) de que esto destruiría las relaciones sociales no acertó plenamente; la tendencia es bien distinta: los poderes mediáticos tratan de convencernos de que la comunidad se construye no por el respeto, sino gracias a esa transparencia o sinceridad sobre intimidades, secretos, cuanto más turbios, más auténticos, y más reales ${ }^{25}$. Nos conformamos con no ser indiferentes o impasibles ante los males actuales, aunque se trate de un $\ll$ sufrimiento distante ${ }^{26}$, pero sin que esto implique cambio alguno en la propia vida.

Atendiendo a las conductas normalizadas por los medios de comunicación podríamos afirmar que la ética contemporánea se sitúa en este nivel sensible del dinamismo emocional. El hambre, las muertes o genocidios en países sin estructuras sociales o económicas son rechazados mediante manifestaciones públicas y demanda de intervención de las instituciones, aunque sabemos que el modo de vida de los países desarrollados contribuye a la pobreza y las guerras. Bauman se ha referido a estos fenómenos mediáticos que recortan la enormidad de las nuevas responsabilidades a la medida de nuestra sensibilidad moral, con el término

\footnotetext{
24 Cfr. Richard SEnNETT, The fall of public Man, Cambridge-New York, 1977.

25 Cfr. Slavoj ZiZEK, Bienvenido al desierto de lo real, Madrid, 2008, p. 21 y ss.

26 Cfr. Luc BolTansKi, La Souffrance à distance, Paris, 1993.
} 
«carnavales de la pena»y «fatiga de la caridad». A golpe de sentimientos no logran cuajar vínculos permanentes y eficaces, sólidamente institucionalizados. Exhiben el sufrimiento humano, pero no exponen sus causas, como si la solidaridad de sofá bastara para cambiar la injusticia ${ }^{27}$.

No hay duda de que la psicologización y el inevitable emotivismo traen consigo un debilitamiento del yo moral; la prioridad de la respuesta emocional sobre el juicio y la reflexión ofrece un sucedáneo de la libertad y de la responsabilidad, que lleva a prácticas verdaderamente paradójicas como la ensayada en algunos países del norte de Europa. Para combatir la creciente xenofobia y la intolerancia sexual (debidas al aumento de trabajadores inmigrantes) crearon las llamadas «bibliotecas vivas»: se paga a miembros de las minorías étnicas o sexuales por visitar a una familia y contar su vida, familiarizarles con su historia, etc. Las limitaciones de este método saltan a la vista: ¿pueden redimir los detalles de la vida personal, las aficiones, la ternura con su perro, etc. de los delitos o males graves que uno haya causado? ${ }^{28}$

Se habla incluso de una perspectiva posmoderna de la moralidad, resultante del ya añejo proceso de autocrítica y desmantelamiento sufrido por la cultura moderna, en la que el eslogan más universal es «sin exceso» y dominan el individualismo más puro y la búsqueda de la buena vida, limitada solamente por la exigencia de tolerancia como indiferencia. En cierto modo, la cultura emocional parece haber llevado a los países desarrollados hacia un callejón sin salida, por su incapacidad para reconocer y perseguir auténticos objetivos sociales de justicia e igualdad. Los conflictos sociales y bélicos, los desplazamientos de población, las formas de explotación e injusticia a gran escala no son sino desafíos para el Estado de derecho, que con frecuencia parece ser el único exponente de la altura moral de la civilización occidental. En las sociedades occidentales hay una tendencia creciente a resolver los conflictos éticos mediante la expansión del derecho hacia ámbitos de la vida cotidiana que hasta hace poco no eran objeto de legislación alguna. Desde hace unas décadas el derecho penal se ha convertido en una de las fuentes de normatividad social en las sociedades desarrolladas. Ya que no podemos apelar a bienes comunes sobre cuyo contenido cabe argumentar, pero cuya vigencia está fuera de duda, incluso para quienes no son capaces de reconocerlos, es urgente transformar en reglas aquello que reúne a una mayoría. La persuasión mediante razones es sustituida por la imposición

27 Zigmunt BAUMAN, La ambivalencia de la modernidad y otras conversaciones, Barcelona, 2002, pp. 195-196.

28 A esta práctica se refiere Slavoj Zizek con ironía (En defensa de causas perdidas, Madrid, 2011, p. 19). 
de una conducta y la penalización. Y en dirección inversa, la permisividad de ciertas conductas, el hecho de reconocerlas como legales abre el camino para que sean vistas como buenas o neutras. Así, es frecuente oír hablar de la tarea de modernización desde las instituciones, desde el derecho; de la educación noformal de las políticas gubernamentales y la configuración de nuevos modelos sociales, del pensamiento correcto auspiciado en el espacio único de los medios de comunicación de masas, etc.

Se socializa la conciencia moral al precio de psicologizar una buena parte del ordenamiento jurídico que incluso llega a legislar sobre convicciones, creencias y prejuicios. Esta fuente de normatividad supuestamente objetiva es en su intencionalidad máximamente subjetiva. Como era de prever, la penalización de lo que no debemos pensar o hacer no es tan eficaz como la despenalización que hace legales acciones que comúnmente son consideradas injustas. A quienes impulsan las nuevas leyes les escandaliza la terca y resistente autonomía del yo moral, que dificulta ese arreglo «perfecto» de la convivencia humana. Se hace cada vez más necesario motivar, conectar emocionalmente con el yo moral de los ciudadanos. Y por eso las estrategias del marketing del civismo apelan exclusivamente a los sentimientos, a la solidaridad emotiva (ante la emigración ilegal, el abuso del alcohol, la velocidad excesiva, la violencia en el ámbito familiar, etc.). El civismo (o la civilidad) ha traído un buen número de normas y prácticas que se imponen obligatoriamente para todos. A las normas de cortesía, respeto, concordia (ruidos, paso, aparcamiento, etc.) se han añadido otras que preparan una vida futura. En los últimos años estas normas y prácticas responden fundamentalmente a situaciones y necesidades propias de países desarrollados, a iniciativas conducentes a transformaciones que prometen bienes comunes innegables: por ejemplo, la distribución de basuras, el reciclaje, la economía en el consumo de energía, el uso de aerosoles. Esta forma de ética cívica tiene la obligatoriedad de normas morales. El ciudadano percibe, como nunca, que no hace las leyes, sino que las consume. El Estado, al mismo tiempo que se presenta como único garante del bienestar social, impone restricciones en ámbitos de la vida familiar, de la vida privada; es decir, moraliza (regula) conductas que hasta hace poco formaban parte de los códigos personales o particulares con los que se rigen muchos aspectos de la vida.

En la línea del paradigma emocional vigente tiene sentido la práctica tan extendida de las concentraciones en lugares públicos para mostrar repulsa o apoyo: de la protesta política, rápidamente se ha pasado a la protesta moral. Estas concentraciones tienen un claro componente moral, de moral cívica, esto es, la suprema forma de moralidad de las sociedades liberales, por eso transcurren 
siempre dentro de unos límites tanto espaciales como gestuales, sin agresiones ni violencia; los gestos deben ser lo más homogéneos posibles para su eficacia: lo que se busca es convertir en universal, en principio de acción normativo algo que se reprueba o se demanda. Lo de menos es si la concentración se produce espontáneamente; lo más sorprendente es que muchas personas canalizan sus emociones del mismo modo. Como señala Bauman, «la individualidad acaba limitándose al acto de ofrecer individualmente lo que todo el mundo se afana por ofrecer ${ }^{29}$; es decir, se conforma con referir las experiencias emocionales propias en gestos que se puedan entender fácilmente, los mismos que utiliza todo el mundo. Como la transformación de esos gestos en patrones de expresión colectiva amenaza con debilitar su eficacia, pues confiamos en los gestos que realmente exteriorizan, que revelan una experiencia interior individual, ¿terminaremos por pasar por alto estos símbolos y gestos que se han estandarizado y, con ello, despersonalizado gracias a su difusión en los medios de comunicación? Si como apunta Hochschild, la burocratización de nuestra sociedad -y, en mi opinión, su homogeneización- estandariza, mercantiliza y despersonaliza todas las demostraciones públicas de sentimientos, también ante este tipo de gestos de protesta o solidaridad que tanto abundan pronto dejaremos de pensar que corresponden a una experiencia real. Los gestos y ritos sociales son necesarios en la vida social, pero vulnerables a la erosión ${ }^{30}$.

Si hace unas décadas se veía con cierta alarma esta deriva ética, la inestabilidad y el activismo social de los últimos años han acentuado la impresión de debilidad política que lleva a que en países de tradición asociativa y democrática, con una buena parte de la población con educación superior, se abra paso con fuerza el populismo, es decir, una forma emocional, casi visceral de participación política. Se habla ya sin reservas de la política de la posverdad, esto es, de un discurso que aspira a dirigir el curso de la acción y la toma de decisiones políticas, como las elecciones democráticas, apoyándose en falsedades, rumores o sencillamente mentiras. El diccionario de Oxford define 'posverdad' como una palabra que «denota circunstancias en las que los hechos objetivos son menos influyentes en la formación de la opinión pública que las emociones o las creencias personales». Al menos habla bien de nuestro tiempo la exigencia de verdad que se da en todos los ámbitos de la cultura y la vida social, desde el arte con su empeño por romper hábitos, hasta el uso de internet y de la información que

29 Ibid., p. 171.

30 Cfr. Arlie Russell HochschILD, La mercantilización..., op. cit., p. 124. 
contiene para conformar una opinión pública más escarmentada, que demande un compromiso con la verdad de aquellas instancias (por ejemplo, Google o facebook) que hasta ahora se pretendían neutrales mientras daban soporte a todo tipo de noticias.

Aunque siempre hay muchos factores en juego, no está exenta de riesgos una sociedad cuyo tejido básico consiste en un entramado de vínculos emocionales. No sólo en política, también en las demás dimensiones de la existencia humana se percibe esta prelación de las vivencias sobre las ideas: en la práctica religiosa, en la educación, etc. Si estamos dando el giro hacia otra cultura, o más bien es un periodo de reajuste de lo antiguo y lo nuevo, es pronto para decidirlo. 

IGLESIA Y ESTADO EN LA AMÉRICA HISPANA ENTRE EL ANTIGUO Y EL NUEVO RÉGIMEN 
